\title{
Symultaniczność i kompilacja a obraz miejsca
}

\section{Grzegorz Nawrot}

\begin{abstract}
Katedra Projektowania Architektonicznego, Wydziat Architektury, Politechnika Śląka w Gliwicach, e-mail: arch_grzegorz_nawrot@poczta.onet.pl
\end{abstract}

Streszczenie: Architektura - jest wydzielaniem przestrzeni, konstruowanym z tworzywa, będącego kompilacją elementów materialnych i niematerialnych. Życie człowieka ma charakter przestrzenny, odbywa się w przestrzeni jego egzystencji: przez niego wytworzonej i zastanej. Człowiek egzystuje w przestrzeni behawioralnej, wśród architektury miasta, która jest swoistym medium - środkiem przekazu informacji składających się sumarycznie na percepcjonowane przez niego treści. Mieszka w przestrzeni realnej i wirtualnej oraz $\mathrm{w}$ przestrzeni będącej synergią zbudowaną z obu.

Węzeł - to miejsce spotkań: pasaży, ulic... Konstruowany jako miejsce formalnie i funkcjonalnie ważne: do spotkań w mieście. Ma swoje działanie synergiczne. Budowanie węzłów - to budowanie możliwości do powstawania potencjalnych Miejsc Strategicznej Interwencji. To miejsca: kreowania zdarzeń i swoista furtka do różnorakich doznań, percepcji świata materialnego i wirtualnego oraz fantasmagorii - będących konsekwencja ich wzajemnych relacji. Konstruują je: znaczenie w geografii miasta, znaczenie użytkowe, uformowanie kubaturowe, wydarzenia historyczne i współcześnie przekazywane informacje.

Miasto, to co prawda duży dom - ale przy założeniu, że węzeł miejski jest projektowany, a nie powstaje przypadkowo, jego wybudowanie - jako obiektu architektonicznego, zespołu takich obiektów bądź założenia urbanistycznego - nie musi być krótsze niż konstruowanie w nim treści.

Słowa kluczowe: Heterotropia, architektura, węzeł, miejsce kompilacyjne, rama dla zdarzeń.

\section{Gmach a rama dla zdarzeń}

Obiekt architektoniczny jest swoistym miejscem, w wydzielonej przestrzeni. Jego ukształtowanie formalne i struktura są emanacją różnorakich zadań, które może wypełniać: tych jednoznacznie utylitarnych a także odniesień, wykraczających poza to pole. Te drugie, konstruują z niego swoisty środek przekazu informacji o: wyznawanych wartościach, odniesieniach do miejsca usytuowania i jego najbliższego sąsiedztwa, prezentowanych wymogach prestiżu społecznego... Przekazywane informacje mają charakter synergiczny a współczesne technologie teletechniczne i informatyczne sprawiają, że dotyczą świata materialnego i wirtualnego...

Obiekt-miejsce w przestrzeni konstruowany jest wielorako. Może stanowić jedynie wydzieloną ramę dla zdarzeń, nie definiując ich rodzaju i sposobu wykonywania. Tak rozumiany, posiada swoisty status przejściowy: dążąc ku - symbolizuje zmienność.

Alternatywnie, stanowiąc filozoficzną metaforę obiektu-gmachu - może jednoznacznie określać rodzaje i sposoby odbywających się działań a także determinować ich chronologię. Gmach - symbolizując niezmienność i stabilizację, wyraża je również niezmiennym przekazem: zawartością trwałych treści i trwałym ukształtowaniem formalnym. Istniejące hybrydy łączą oba te podejścia... 
Węzeł miejski jest pojęciem analogicznym acz o szerszym, w skali działania, znaczeniu. Jest zatem również swoistym miejscem, w wydzielonej przestrzeni a jego ukształtowanie formalne i struktura są także emanację różnorakich zadań, które wypełnia. Jak obiekt architektoniczny, stanowi zatem wydzieloną ramę dla odbywających się zdarzeń, bądź jednoznacznie określa ich rodzaje oraz sposoby odbywania się determinując ich chronologię, albo - jako hybryda, łączy oba te podejścia...

\section{Na przecięciu świata ludzkiego i materii rodzi się miejsce ${ }^{1}$}

Dzieje świata składają się z nieskończonego ciągu faktów zastygłych w formie rzeczy². $Z$ drugiej strony, coraz większa ilość współczesnych faktów traci właściwość do zastygania w owej stabilności. Na przecięciu świata ludzkiego i materii rodzi się miejsce $e^{3}$.

W pierwszym przypadku, jednoznacznie usytuowane i zbudowane stabilnie ukształtowaniem struktury - determinuje rodzaj i kolejność działań, w nim się odbywających. W przypadku obiektu architektonicznego bądź zespołu urbanistycznego - to filozoficzna metafora nieprzekształcalnego budynku-gmachu.

W drugim - tracąc zastygły charakter, jest konstruowane przez zdarzenia, które jak pisze Krystyna Rembowska, wiążą się z przestrzenią i ruchem w nierozerwalny układ, kreując przestrzeń wielowymiarową, dynamiczną i otwartą. Tworzą miejsca, stające się kluczową kategorią identyfikującą i opisującą wydarzeniowy charakter miasta ${ }^{4}$. Owe miejsca-ramy dla odbywania zdarzeń w event-cities.

W przypadku rozpatrywania miejsc w kontekście społeczeństwa postindustrialnego, łączą w jednym wiele przestrzeni i punktów wzajemne nieporównywalnych, stając się swoistą heterogenną emanacją dynamicznego działania - miejscami spotkań dla castellsowskiego la societe des $f u x^{5}$ : mieszkańców, turystów, informacji, kapitału, wyrobów, obrazów a także - idei, zmian ról w relacjach społecznych, interpretacji rzeczywistości.

Dzieje tak pojmowanych pasaży miejskich, owych ulic i placów - składają się z interdyscyplinarnych ciągów zastygłych nie tylko w formie rzeczy. Sformułowana przez Schopenhauera iluzja, zgodnie z którą do uchwycenia istoty historii wystarczy porównać pisma Herodota $\mathrm{z}$ informacjami z porannej prasy, nabiera wernakularnej treści ${ }^{6}$. Wyrazem jest tak zwana historia kultury, zestawiająca punkt po punkcie wykaz form życia i tworów ludzkości ${ }^{7}$.

Miasto to Pasaże. Rozumiane wielorako: jako pasaże form bądź elementów użytkowych, wartości, zapisanych wspomnień czy użytecznych bądź bezużytecznych informacji.

Miasto to również pasaże poszczególnych ulic. Także rozumiane wielorako: ulic współczesnych form bądź elementów użytkowych, ulic współczesnych wartości, ulic zapisanych wspomnień czy ulic współczesnych użytecznych bądź bezużytecznych informacji.

Ulica jest tworem kultury. Zestawia ciąg faktów zastygłych w formie rzeczy, stanowiąc owy, wspomniany przez Waltera Benjamina, wykaz form życia i tworów ludzkości ${ }^{8}$. $\mathrm{Z}$ jednej strony, wprowadzone tym sposobem w skarbcu kultury bogactwa ukazują się jako

\footnotetext{
Rembowska Krystyna, 2008.

Benjamin Walter, 2005, s. 46.

Rembowska Krystyna, ibidem

4 Rembowska Krystyna, s. 6, ibidem.

5 la societe des flux; tłum. - społeczeństwo przepływu; pojęcie Manuela Castellsa, [w:] Castells Manuel, 1989.

6 Benjamin Walter, 2005, s. 46.

Benjamin Walter, ibidem.

Benjamin Walter, ibidem
} 
jednoznaczne i raz na zawsze określone ${ }^{9}$. Z drugiej - wprowadzenie pomiędzy nie elementu tworzywa niematerialnego, powoduje, że te materialne, uzyskując swoisty dynamizm, ukazują się jako niejednoznaczne i nieokreślone „raz na zawsze ${ }^{10}$ ”. Niematerialna informacja, pod postaciami koloru, dźwięku bądź informatyczna „furtka” do świata wirtualnego, konstruuje system, w którym mieszają się wytwory rzeczywistości materialnej i wirtualnej, owej fourierowskiej kolorowej wizji i cyfr.

Tak rozumiana ulica, konstruuje system, połączonych materialnych form kubaturowych, wizji dźwięków i światła, wirtualnych otwarć i mentalnych skojarzeń. Istotne w nim znaczenie uzyskuje fantasmagoria, oddziałująca na obserwatora. Nasuwa się nieuchronnie skojarzenie z fourierowską Harmonie, w której istotą funkcjonowania społeczeństwa - są namiętności, będące siłami napędowymi jego skutecznego funkcjonowania ${ }^{11} \ldots$

\section{Węzel}

Miasto, jako benjaminowski zespół Pasaży, to mentalna emanacja materialnie skonstruowanych pasaży i placów. Te pierwsze - to ulice i układy przyrodnicze, czyli korytarze miejskie. Drugie - mogą koncentrować funkcje miejsc węzłowych ${ }^{12}$. Węzeł to szczególne miejsce w zurbanizowanej przestrzeni fizycznej i wirtualnej, w którym krzyżują się linie powiązań o charakterze transportowym, komunikacyjnym/informacyjnym, kapitałowym, energetyczny, itp. ${ }^{13}$. Budowanie węzłów - to budowanie możliwości do powstawania potencjalnych Miejsc Strategicznej Interwencji (MSI) ${ }^{14}$. Węzeł - to miejsce spotkań: pasaży, ulic... Konstruowany jako miejsce formalnie i funkcjonalnie ważne: do spotkań w mieście. Ma działanie synergiczne. To miejsce: kreowania zdarzeń i swoista furtka do różnorakich doznań, percepcji świata materialnego i wirtualnego oraz fantasmagorii - będących konsekwencja ich wzajemnych relacji. Konstruują je: znaczenie w geografii miasta, znaczenie użytkowe, uformowanie kubaturowe, wydarzenia historyczne i współcześnie przekazywane informacje.

Architektura - jest wydzielaniem przestrzeni, konstruowanym z tworzywa, będącego kompilacją elementów materialnych i niematerialnych. Wspomniane la societe des flux to, cytując za Manuelem Castellsem i Krystyną Rembowską - współczesne społeczeństwo przepływu informacji, kapitału, wyrobów, obrazów, turystów, zmian ról w relacjach społecznych, idei, interpretacji rzeczywistości. Węzeł synergiczny, rozważany w kontekście społeczeństwa przeplywu - to heterotropiczna synteza elementów skonstruowanych materialnie i wirtualnie, ich mentalnych emanacji i bieżąco przekazywanych informacji ${ }^{15}$. Istotne znaczenie ma komunikacja: węzeł jest konstruowany przez przepływ informacji, ludzi i przedmiotów. Może przekazywać informacje a także stanowić ich źródło. Jako medium ich przekazu - oddziałuje wielopłaszczyznowo na kilka zmysłów a odniesiony do teorii McLuhana - ma charakter środka zimnego ${ }^{16}$. Richard Sennett, pisząc Ciało i kamień. Człowiek i miasto $w$ cywilizacji

\footnotetext{
9 Benjamin Walter, ibidem

10 Takim elementem może być informacja pod różnymi postaciami: kolor, dźwięk bądź informatyczna „furtka” do świata wirtualnego.

11 Benjamin Walter, ibidem, s. 48-49.

12 Zbigniew Zuziak wymienia korytarze miejskie, miejsca węzłowe i korytarze zielone, w kontekście konstrukcji urbanistycznej miasta; [w:] Zuziak Zbigniew K., 2016.

13 Zuziak Zbigniew K, 2011.

14 MSI - za Zuziak Zbigniew K, 2011.

15 Heterotopia, za: Foucault (1980): łączenie w jednym punkcie wielu przestrzeni i punktów wzajemnie nieporównywalnych.

16 Środek gorący oddziałuje, z dużą wyrazistością, na jeden zmysł - zimny, równocześnie na kilka, pozostawiając interpretację informacji odbiorcy... za Marshall McLuhan, Lampham Lewis H, 1994.
} 
Zachodu, uważał, że rytuały powinny stać się spoiwem miasta ${ }^{17}$. Informacje, przekazywane w węzłach, budując owe rytuały - mogą konstruować tę spoistość.

Węzeł synergiczny może funkcjonować $\mathrm{w}$ różnorakiej skali a jako miejsce - być pojmowany wielorako: miejsce abstrakcyjnie wydzielone z przestrzeni, o nieprzyporządkowanych pierwotnie funkcjach i przeznaczone do wypełniania potencjalnymi treściami (rama dla zdarzeń w event-city bądź miejsce - gmach), komunikacyjne, element domu w mieście ${ }^{18}$, itp.

W pierwszym przypadku, to wieloznaczeniowe i wieloużytkowe miejsce usytuowania znaczących funkcji usługowych. Miejsce na umówione spotkanie w mieście i równocześnie miejsce dla zdarzeń - także swoista rama dla emanacji otwieranych emocji. Jego potencjalnie użytkowa wielowarstwowość - to również nakładanie różnorakich możliwości interpretacyjnych: politycznych, społecznych, gospodarczych a także - budowania interpretacji współczesnych odniesień do wartości, kształtowanie rytuałów, integrowanie, itp. ${ }^{19}$ Kompilacja funkcji użytkowych i znaczeń archetypowych, użytych elementów materialnych i wirtualnych oraz relacji pomiędzy nimi - konstruuje hybrydę, wnoszącą w przestrzeń swoistą wartość dodaną. Fakt zaistnienia synergii - stwarza możliwość powstawania owej wartości dodanej.

W drugim - czyli rozważany w kontekście układu komunikacyjnego, generuje ruch ludzi, przepływ towarów oraz informacji, skupiając aktywności i wiążąc je z zagospodarowaniem przestrzennym miasta.

$\mathrm{W}$ trzecim - to element bądź elementy domu kompilacyjnego. Dom budowany przez lata zarówno w sferze idei, jak i w sferze materii był rozumiany adekwatnie do swoich czasów: zarówno do stanu umysłu, jak i stanu aktualnego rozwoju cywilizacyjnego we wszystkich dziedzinach życia. Był tych stanów emanacjąa ${ }^{20}$. Początkiem domu jest miejsce do sporządzania i spożywania posiłków i bezpieczne miejsce do spania. Wokół niego zaczynają być wykonywane wszystkie podstawowe czynności związane z życiem człowieka ${ }^{21}$.

Dla Otto Friedricha Bolnowa mieszkać - oznacza być w domu ${ }^{22}$. Konsekwencją jest, że - mieszkanie $w$ mieście, interpretuje to miasto jako swoisty duży dom. Taki był również, pogląd Leona Battisty Albertiego. Patrząc na węzty miejskie nie tylko jak na miejsca krzyżowania się materialnie ukształtowanych dróg komunikacyjnych - można uznać, że niektóre z nich mogą generować elementy domu, usytuowane poza budynkiem mieszkalnym. Jeżeli zatem miasto jest dużym domem, to wybrane elementy tego domu - znajdują się w przestrzeni publicznej, w stanie rozproszenia. Są odpowiednikami bądź substytutami - miejsc wspólnych w lokalu mieszkalnym. Odnajdywanie elementów domu w przestrzeni miasta i posługiwanie się nimi jako substytutami przestrzeni zamkniętych w kubaturze budynku-gmachu - konstruuje dom kompilacyjny. Jest również swoistą dyskusją dwóch filozoficznych metafor: domu-gmachu i doти kompilacyjnego ${ }^{23}$. Stopnie intensyfikacji pojawiania się zjawiska domu kompilacyjnego polegają na nasileniu się tendencji do redukowania pomieszczeń kształtowanych w sposób materialny w mieszkaniu-lokalu - na rzecz przestrzeni „otwartych”, których

\footnotetext{
17 Sennett Richard, 1996.

18 Odniesienie do teorii Leone Battisty Albertiego porównującego miasto do domu.

19 Max Scheler - wyróżniał obiektywną hierarchię pięciu rodzajów wartości, z których każda wyższa nadaje sens niższej: religijne (świętość odnoszona również do obiektywnej rzeczywistości), duchowe, witalne, hedonistyczne, utylitarne.

${ }^{20}$ Nawrot Grzegorz, 2015, s. 17.

${ }^{21}$ Ibidem.

22 Według Otto Friedricha Bollnowa: Eigenraum (za Noldem Egenterem: indywidual space).

${ }^{23}$ Autor odnosi się do tego [w:] Nawrot Grzegorz, 2015.
} 
użytkowanie może być wielofunkcyjne ${ }^{24}$. Węzły - to przestrzenie o dużym nasyceniu funkcjami istotnymi dla zamieszkiwania w domu kompilacyjnym.

Kevin Lynch, uznający projektowanie miast za sztukę, pisał że opiera się ona na upływie czasu, ale rzadko daje możliwości posługiwania się kontrolowanymi i ograniczonymi sekwencjami, które są charakterystyczne dla innych sztuk ${ }^{25}$. Dom narasta. Ten usytuowany w budynku i ten duży - w mieście. Czas wznoszenia budynku, jako miejsca przeznaczonego do wypełnienia treścią domu - jest zdecydowanie krótszy niż budowanie tejże treści.

Przy założeniu, że węzeł jest projektowany a nie powstaje przypadkowo, jego wybudowanie - jako obiektu architektonicznego, zespołu takich obiektów bądź założenia urbanistycznego - nie musi być krótsze niż konstruowanie w nim treści.

\section{Symultaniczność i kompilacja}

Życie człowieka ma charakter przestrzenny, odbywa się w przestrzeni jego egzystencji: przez niego wytworzonej i zastanej ${ }^{26}$. Człowiek egzystuje w przestrzeni behawioralnej, wśród architektury miasta, która jest swoistym medium - środkiem przekazu informacji składających się sumarycznie na percepcjonowane przez niego treści. Mieszka w przestrzeni realnej i wirtualnej oraz w przestrzeni będącej synergią zbudowaną z nich obu ${ }^{27}$.

Architektura jest językiem zdolnym do przekazywania znaczenia, a także porządkującym zachowania użytkowników przestrzeni, którzy się w niej znajdują. Jedną z najistotniejszych kategorii decydujących o jej kształtowaniu jest chronologiczne (liniowe) bądź symultaniczne odniesienie się do czynności określających stan jej użytkowania ${ }^{28}$.

Symultanizm - jest przekazywany za pomocą słowa tymczasem. Adekwatnie rozumiana symultaniczność w przestrzeni architektonicznej - może być dwojaka: jako równoczesność działań fizycznie wykonywanych przez użytkowników bądź jako równoczesność zachodzących w niej różnorakich procesów, w tym wykorzystujących współczesne technologie teletechniczne i informacyjne, których podmiotami mogą być jej użytkownicy.

W pierwszym przypadku, istotne znaczenie ma ukształtowanie wydzielonej przestrzeni, umożliwiające takie działania. W drugim - adekwatne jej skonstruowanie oraz nasycenie różnorodnymi elementami komunikacji i środkami przekazu, umożliwiającymi ową symultaniczność. Przekaz odbywa się wówczas równocześnie z wielu źródeł, za pośrednictwem wielu nośników, w tym również reprezentujących współczesne technologie informatyczne i teletechniczne.

Kolejną kategorią jest kompilacyjność użytkowanej przestrzeni obiektu architektonicznego bądź założenia urbanistycznego. Miejsce kompilacyjne - składa się z wielu miejsc i nie-miejsc. Tak funkcjonujące, zatraca swoja metafizyczną metaforę spójnego i jednoznacznego w percepcji - pojedynczego gmachu. Rozdzielone w przestrzeni na wiele lokalizacji - ulotne, rozpływa się w rzeczywistości. Z jednej strony - to rozszerzenie dotychczasowo rozumianej przestrzeni behawioralnej, z drugiej - jej substytut z możliwą wirtualną emanacją wszystkich rzeczywistych eksponatów, które mogą się niej znajdować.

Węzeł - owe miejsce szczególne w wydzielonej, zurbanizowanej przestrzeni fizycznej

\footnotetext{
24 Nawrot Grzegorz, ibidem, s. 140.

${ }^{25}$ Lynch Kevin, 2011, s. 1.

${ }^{26}$ Martin Heidegger, zarysowując pojęcie bytu i bycia, odnosi się do przestrzeni egzystencjonalnej, czyli do tej, w której egzystuje bycie człowieka (byt, Dasein). Heidegger Martin, 2007.

27 Nawrot Grzegorz, ibidem, s. 199.

${ }_{28}$ Nawrot Grzegorz, ibidem, s. 164.
} 
i wirtualnej, w którym krzyżują się linie powiązań o charakterze transportowym, komunikacyjnym/informacyjnym, kapitałowym, energetycznym - może być konstruowany adekwatnie.

\section{Podsumowanie}

Przestrzeń miasta jest konstruowana z coraz to większej liczby elementów. Obok materialnych, budują ją przestrzenie wirtualne i nowe formy przez nie kształtowane. W takim kontekście, pojęcie węzła-zmienia swój jednoznaczny charakter, poszerzając się o kolejno oswajane nowe przestrzenie. $Z$ jednej strony, dotyczy to dotychczasowo pojmowanego metaforycznego gmachu, które sytuowało go w konkretnym, wyznaczonym materialnymi granicami miejscu, z drugiej - współczesne technologie poszerzyły to miejsce w przestrzeni wirtualnej, odnajdując w niej zarówno nowe miejsca, jak i komunikację nowego typu.

Otwieranie ich w wymiar pozakubaturowy, a także synergia przestrzeni architektonicznej z różnorakimi innymi przestrzeniami przewartościowuje paradygmaty myślenia o mieście i ma wpływ na projektowanie urbanistyki i architektury.

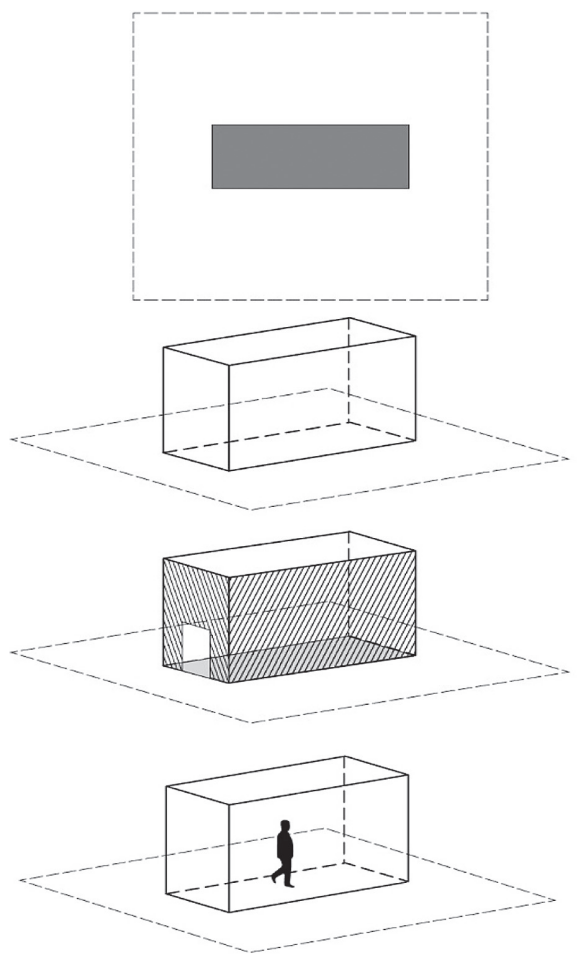

Miejsce - architektura gmachu

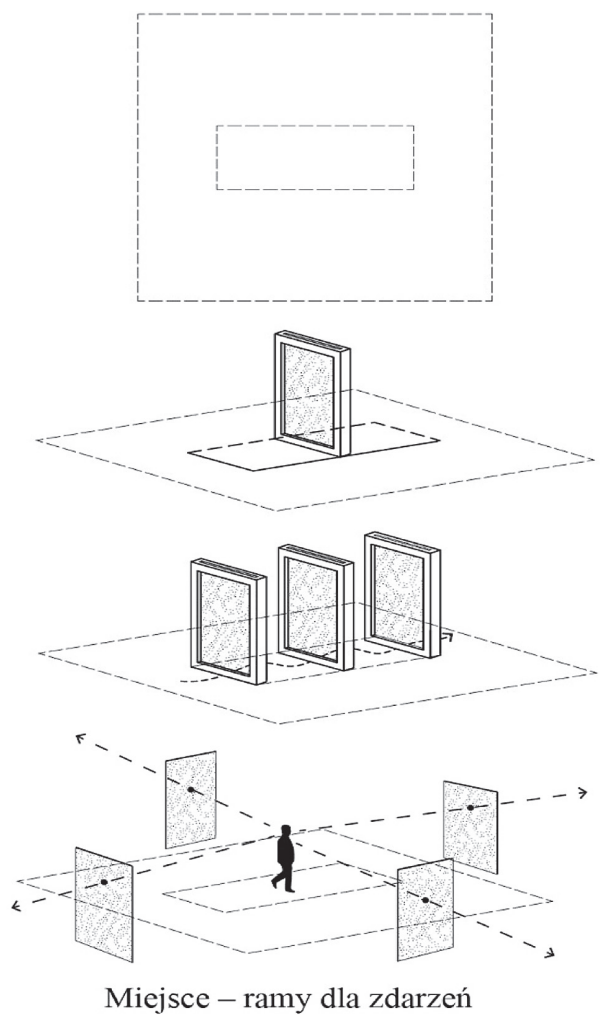

Miejsce - ramy dla zdarzeń

Rys. 1. Interpretacja miejsca jako filozoficznej metafory gmachu i ram dla zdarzeń 

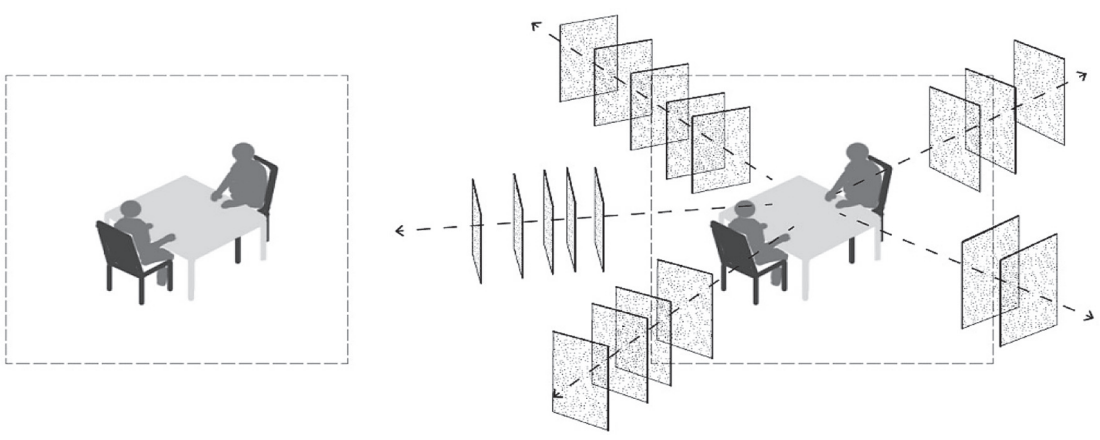

Rys. 2. Miejsca spotkań. Jednoznacznie określone w przestrzeni realnej - jako filozoficzna metafora gmachu vs odnajdywane w synergii przestrzeni realnej i wirtualnej
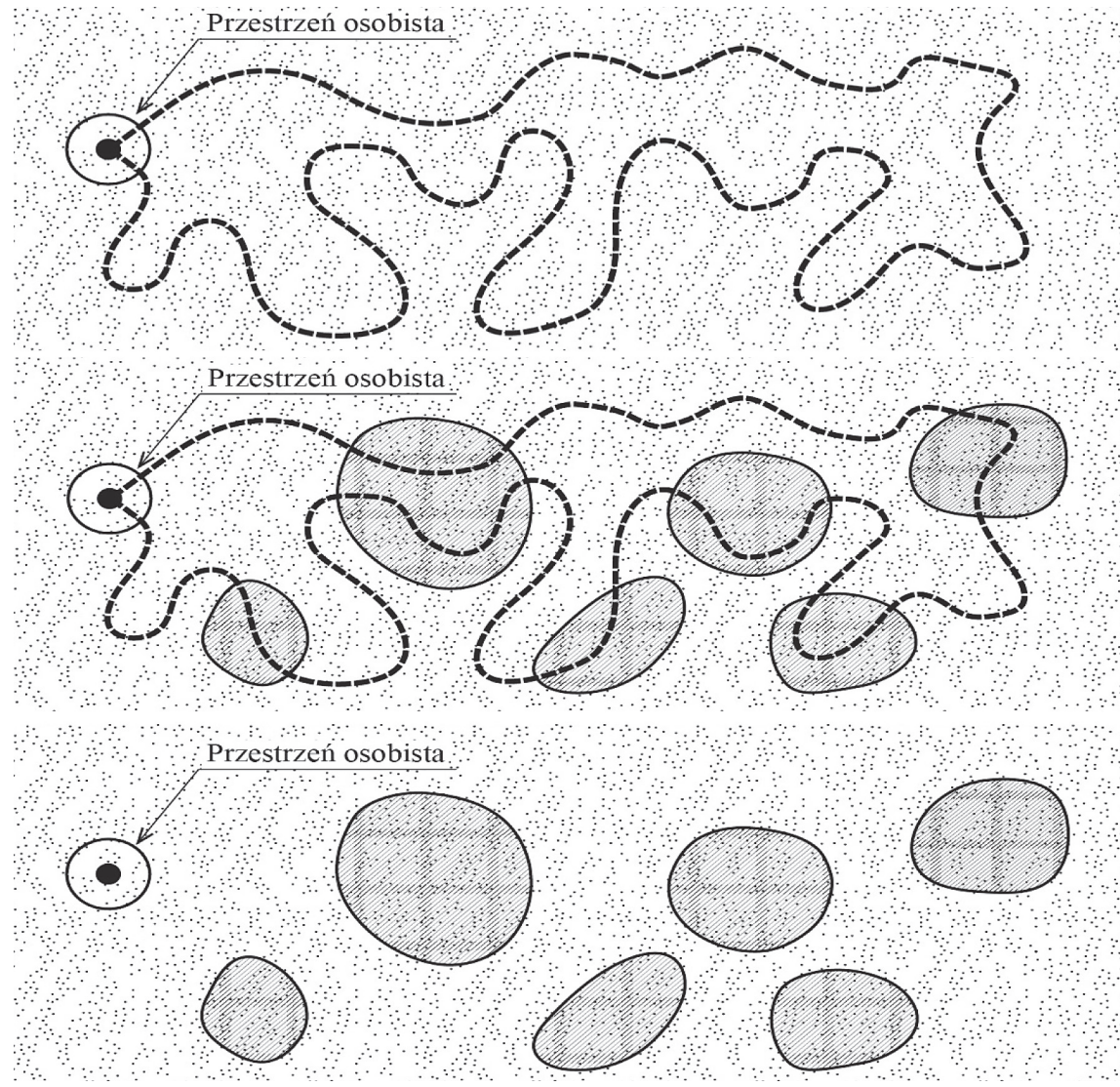

Rys. 3. Przestrzenie, na wspólnym poziomie miejskim, jako - swoiste pokoje dzienne w domu. Interpretacja graficzna zjawiska węzłów w mieście, będących odzwierciedleniem wybranych elementów domu kompilacyjnego 


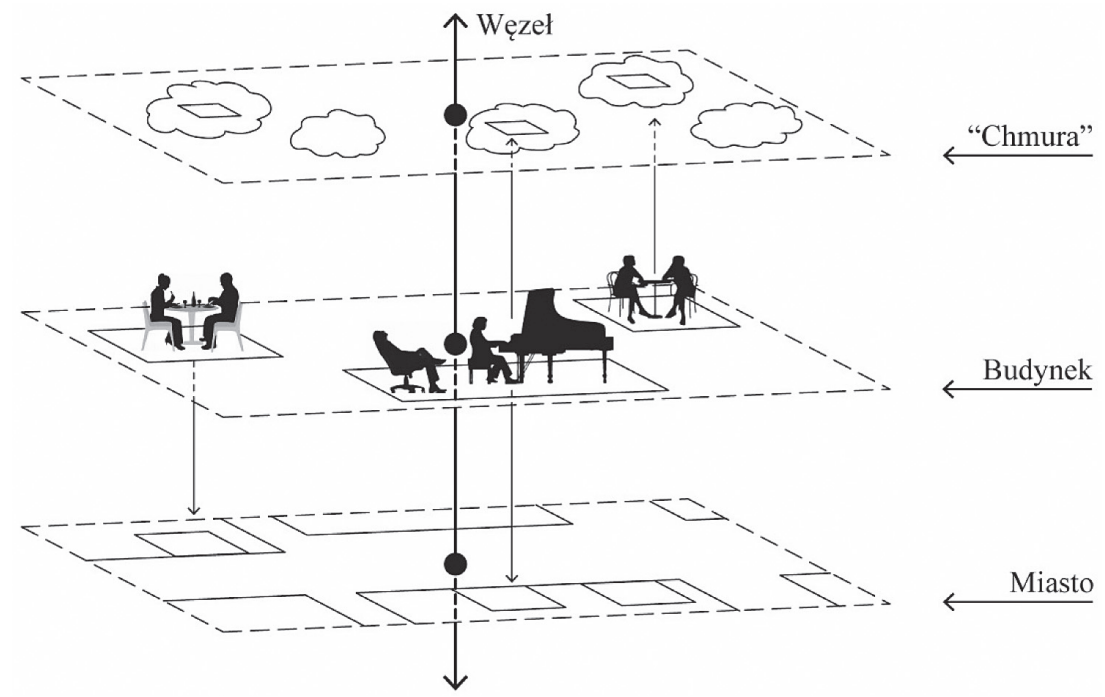

Rys. 4. Węzeł kompilacyjny. Niektóre węzły mogą generować elementy domu, usytuowane poza budynkiem mieszkalnym

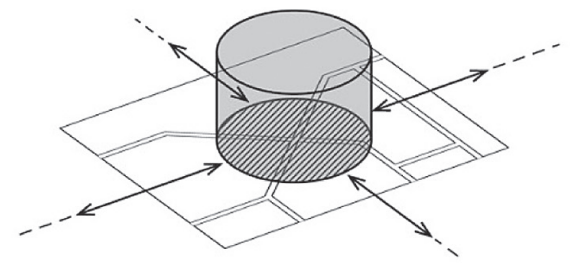

Węzel - architektura gmachu, ksztaltowany w przestrzeni realnej

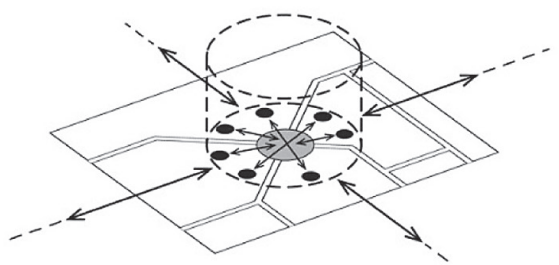

Węzel - kompilacyjny, kształtowany w przestrzeni realnej

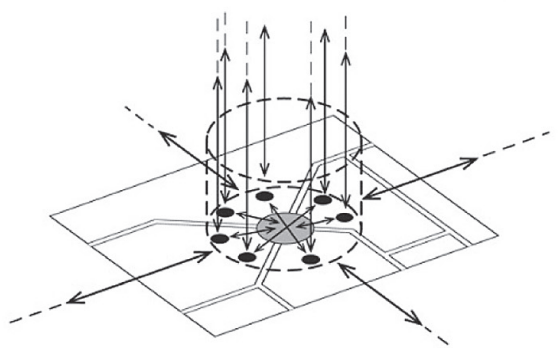

Węzel - kompilacyjny, ksztaltowany w synergii przestrzeni realnej i wirtualnej

Rys. 5. Węzeł w kontekście działań 


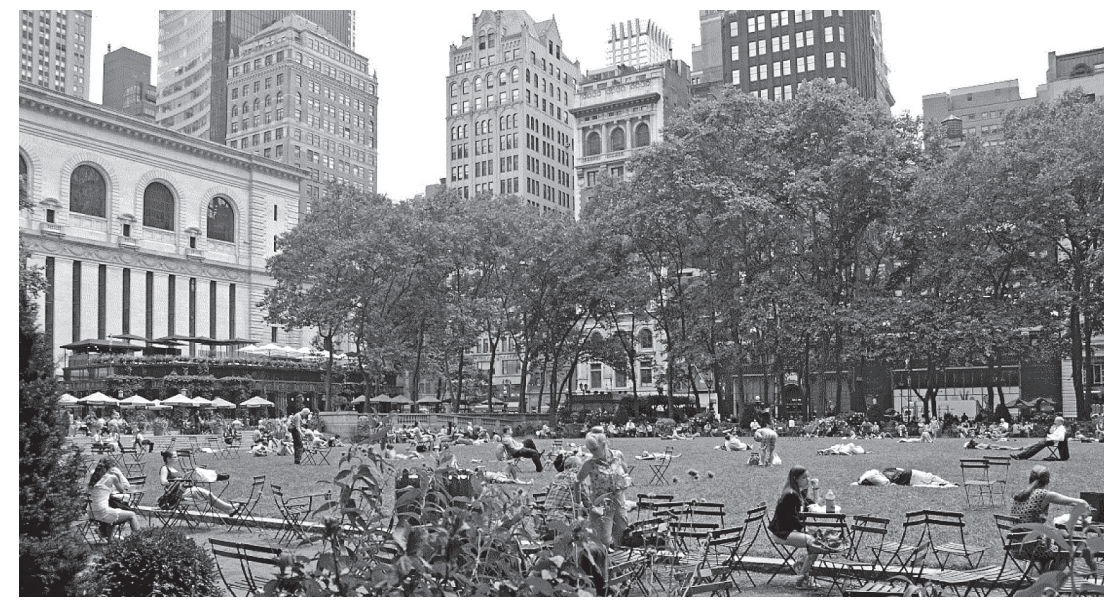

Rys. 6. Przestrzeń umożliwiająca symultaniczne wykonywanie poszczególnych czynności. Miejsce na umówione spotkanie i równocześnie miejsce dla zdarzeń - także swoista rama dla emanacji otwieranych emocji. Jego potencjalnie użytkowa wielowarstwowość - to nakładanie różnorakich możliwości interpretacyjnych - Bryant-Park, Manhatan

\section{Literatura}

[1] Rembowska K. Miasto postmodernistyczne. Perspektywy badań geograficznych. Acta Universitatis Lodziensis, Folia Geografica Socio- Oeconomica 0, 2008.

[2] Benjamin W. Pasaże. Wydawnictwo Literackie, Kraków, 2005.

[3] Castells M., The Informational City: Information, Technology, Economic Restructuring and the Urban-Regional Process, Oxford UK, Cambridge, Mas., 1989.

[4] Zuziak Z.K. Problemy planowania przestrzennego w polskich metropoliach. Kraków 08.09.2016.

[5] Zuziak Z.K. Strategiczne węzły w przestrzeni przepływów. Czasopismo Techniczne 1-A/2011.

[6] McLuhan M., Lapham L.H. Understanding Media: The Extensions of Man. Massachusetts Institute of Technology, 1994.

[7] Sennett R. Ciało i kamień. Człowiek i miasto w cywilizacji Zachodu. Wydawnictwo Marabut, Gdańsk, 1996.

[8] Bollnow O.F. Lived-space. Philosophy Today 5(1) (1961) 31-39.

[9] Nawrot G. O wspótczesnych formach zamieszkiwania w mieście. Gliwice, 2015.

[10] Lynch K. Obraz miasta. Wydawnictwo Archivolta, Kraków, 2011.

[11] Heidegger M. Bycie i czas. PWN, Warszawa, 2007.

\section{Simultaneity and compilation versus image of a place}

\section{Grzegorz Nawrot}

Department of Architectural Design, Faculty of Architecture,

Silesian University of Technology in Gliwice, e-mail: arch_grzegorz_nawrot@poczta.onet.pl

Abstract: Architecture - is demarcation of space, built of material which is a compilation of tangible and intangible elements. Human life is of spatial nature, it takes place 
in space of man's existence: created by him and found by him. A man exists in behavioural space, among architecture of the city which is kind of a medium - means of communicating information cumulating into the contents perceived by him. A man lives in real and virtual space as well as in a space which is a synergy of them both.

Junction - is a meeting place: of walkways, streets... Constructed as a place formally and functionally important: for meetings in the city. It has its synergic function. Constructing junctions - means building possibilities for prospective Places for Strategic Intervention. These are places: for creating events and a kind of gate into different sensations, perception of material and virtual world and phantasmagorias - which are a consequence of their interrelationships. They are constructed by: significance in the geography of the city, usability, volumetric form, historical events and contemporarily broadcast information.

Keywords: Heterotrophy, architecture, junction, compilation place, frame for events. 